\title{
Effects of Temperature, Wetness Duration, and Leaflet Age on Infection of Strawberry Foliage by Phomopsis obscurans
}

\author{
M. Nita, M. A. Ellis, and L. V. Madden, Department of Plant Pathology, The Ohio State University, Wooster, \\ 44691
}

\begin{abstract}
Nita, M., Ellis, M. A., and Madden, L. V. 2003. Effects of temperature, wetness duration, and leaflet age on infection of strawberry foliage by Phomopsis obscurans. Plant Dis. 87:579-584.

Temperature, leaf wetness, and leaflet age effects on infection of strawberry foliage by Phomopsis obscurans were examined in controlled-environment experiments. A mid-season ('Honeoye') and early-season ('Earliglow') cultivar were used. Tested temperatures were 10, $15,20,25,30$, and $35^{\circ} \mathrm{C}$, and tested wetness periods were $5,10,15,20,25$, and $35 \mathrm{~h}$. Leaflets were labeled based on age: 0 to 1, 2 to 6 , and 7 to 14 days old. Effects of temperature, wetness duration, and leaflet age on the logit of disease incidence and severity were quantified using a linear mixed model analysis of variance (ANOVA). Age, wetness duration, and their interaction significantly affected these measures of disease. Disease intensity decreased dramatically with increasing leaflet age at the time of infection, indicating a decrease in susceptibility with maturation of foliage, and increased with increasing wetness duration. Temperature only affected disease incidence with 'Honeoye'. A prediction model was developed for leaflet infection based on ANOVA results. Coefficients of determination were approximately 0.8 for both cultivars and measures of disease (incidence and severity), indicating that disease could be described accurately based on environmental conditions and leaflet age.
\end{abstract}

Phomopsis leaf blight of strawberry (Fragaria $\times$ ananassa) is caused by the fungus Phomopsis obscurans $(12,16)$. The fungus can infect foliage, runners, petioles, and fruit $(5,11,12)$, although fruit infections are not common in the northern United States. Foliar lesions of $P$. obscurans are irregular, often circular, a darkbrown center surrounded by light-brown rings with purplish halos; as disease develops, lesions becomes V-shaped, with the widest part of the $\mathrm{V}$ toward the leaf margins. It is assumed that infection and possible defoliation due to heavy infection reduces yield, weakens plants, and affects winter survival $(4,8)$.

The foliar phase of this disease is very common in the field, and most commercial strawberry cultivars are susceptible (9). Fungicides such as Nova (myclobutanil) are highly effective at controlling Phomopsis leaf blight $(13,14)$; however, because of the sporadic nature of the disease $(17,18)$, fungicide applications generally are not required on a regular basis. Therefore, a

Corresponding author: L. V. Madden

E-mail: madden.1@osu.edu

Salaries and research support were provided by State and Federal Funds to The Ohio Agricultural Research and Development Center (OARDC), The Ohio State University.

Accepted for publication 30 December 2002.

Publication no. D-2003-0310-01R

(C) 2003 The American Phytopathological Society forecasting system would be desirable to identify environmental conditions favorable for infection and to schedule fungicide applications.

There are only a few published reports on the environmental conditions required for infection of strawberry leaves by $P$. obscurans or for any other disease-cycle component. The only study on foliar infection (5) tested wetness periods of mainly $24 \mathrm{~h}$ or longer, although such long periods of free moisture are not common under field conditions. Moreover, in this report (5), only a single wetness duration was used at most temperatures tested; in addition, temperature was controlled only during the post-inoculation (dry) period, not during the infection period. In the same study, Eshenaur and Milholland (5) showed that disease resistance increases with leaflet age. This may appear to contradict the conventional view of the disease because, in the northern United States, Phomopsis leaf blight is most apparent at and after harvest, when many older leaflets are present.

The objectives of this study were to (i) quantify the influences of temperature and leaf wetness duration during the inoculation period on strawberry leaflet infection by $P$. obscurans, (ii) determine the effects of leaflet age on infection, and (iii) develop an empirical model to describe infection in relation to the environment and leaflet age.

\section{MATERIALS AND METHODS}

Host production and preparation. Strawberry plants ('Honeoye' and 'Ear- liglow') were grown from transplants for 5 to 6 weeks in a greenhouse. Both cultivars are short-day plants ('June bearers') and commercially grown in Ohio and other northern states. The soil mix used was sand:peat:steam-disinfested loam (1:2:2 by volume), and plants were grown in plastic pots ( 12 by 10.5 by $15 \mathrm{~cm}$ ). In order to minimize water splash on the leaves, an automatic drip irrigation system was used, and deionized water was supplied to plants. Leaflets were labeled twice weekly by the date of emergence. At the time of inoculation, three categories of leaflet age were selected: 0 to 1 day old (leaflet was not fully opened; labeled 'Young'), 2 to 5 days old ('Intermediate'), and 6 to 14 days old ('Old').

Inoculum production and inoculation. A culture of $P$. obscurans was isolated from an infected leaflet from a commercial field near Wooster, $\mathrm{OH}$. This culture was maintained on fresh potato-dextrose agar (PDA; approximately $22 \mathrm{ml}$ in a 100-by15-mm plastic petri dish), and transferred onto new PDA every 2 weeks. Cultures were stored at $22^{\circ} \mathrm{C}$ under continuous fluorescent light at $58 \mu$ Ein $\mathrm{m}^{-2} \mathrm{~s}^{-1}$ for 21 to 25 days. In order to maintain pathogenicity of the fungus, the fungus was reisolated from an inoculated leaflet attached to a living plant every 3 to 4 weeks.

A conidial suspension was obtained by flooding a PDA plate with a 14-day-old fungal colony with $\approx 10 \mathrm{ml}$ of sterilized water, waiting $\approx 2 \mathrm{~min}$, and then facilitating the release of conidia by gently rubbing pycnidia with a size 1 paint brush. The suspension was filtered through four layers of cheesecloth and conidial density of the inoculum suspension was adjusted to $5 \times$ $10^{6} / \mathrm{ml}$ with aid of a hemacytometer.

The inoculum suspension was applied with an atomizer on both sides of leaflets. On average, there were approximately 3.28 $\mathrm{ml}$ of inoculum suspension per leaflet, giving $\approx 2.6 \times 10^{6}$ spores $/ \mathrm{cm}^{2}$ of leaflet surface. All leaflets of entire plants were inoculated and incubated in a growth chamber with continuous light. Plants were placed in semitransparent plastic bags $(\approx 45$ liters, 0.75 mil thick). In each plastic bag, the entire plants were misted with the inoculum suspension, and two sheets of paper towel, which were wetted with 250 $\mathrm{ml}$ of water, were placed in the bottom of the bag in order to maintain free moisture. Preliminary tests showed that the leaflets 
stayed wet for up to 2 days in the bag at $20^{\circ} \mathrm{C}$. During the experiment, distilled water was sprayed onto leaflets several times as needed according to the leaflet wetness recorded.

Environmental conditions. Tested temperatures $(T)$ were $10,15,20,25,30$, and $35^{\circ} \mathrm{C}$, and tested leaf wetness durations $(W)$ were $5,10,15,20,25$, and $35 \mathrm{~h}$. Temperature and leaf wetness in the growth chamber were measured with a thermister (Model 101, Campbell Scientific, Logan, UT) and printed-circuit wetness sensor (Campbell Model 237), respectively. Measurements were recorded every $5 \mathrm{~min}$ with a $21 \mathrm{X}$ datalogger (Campbell Scientific). A WatchDog datalogger model 130 (Spectrum Technologies, Inc., Plainfield, IL) was used to measure and record temperature and leaf wetness in plastic bags every $5 \mathrm{~min}$. Chambers were set so that the air temperatures inside the bag reached the desired temperature. For each $T$ and $W, 9$ leaflets of each age were selected (27 leaflets per temperature and wetness) for disease assessment.

After inoculation, plants were placed in a greenhouse where temperature ranged from 18 to $30^{\circ} \mathrm{C}$. In order to prevent water splash onto leaves, an automatic trickle irrigation system with deionized water was used, and plants were kept for 5 weeks after inoculation. During the second and third week after inoculation, plants were exposed in a growth chamber to $35^{\circ} \mathrm{C}$ for $48 \mathrm{~h}$ without watering. The high temperature post-inoculation treatment was designed to stress plants sufficiently to "break" the possible latent phase of the disease (5). Preliminary tests indicated that high-temperature treatments of more than 2 days would kill plants, whereas treatments of 1 day would give the same results as no post-inoculation heat treatment. Without the high-temperature stress, few symptoms appeared before the fourth week after the inoculation. For instance, in a preliminary study, mean leaflet disease incidence at 4 weeks after inoculation was 97 and 58\% with and without a high-temperature stress, respectively (M. Nita, unpublished).

'Honeoye', a short-day mid-season cultivar, was used for the main experiment for determining $T, W$, and leaflet age $(A)$ effects on infection. A smaller study was conducted with 'Earliglow', a short-day, early-season cultivar, in which only temperatures of 10,20 , and $35^{\circ} \mathrm{C}$ and wetness durations of 5,20 , and $35 \mathrm{~h}$ were evaluated. Other procedures were the same as described for Honeoye. This cultivar was used to validate results from Honeoye. The experiments were performed three times for each cultivar.

Assessment of disease. Leaflet disease incidence and severity were determined by visual observations at the fourth week after inoculation. Incidence was recorded as the fraction of leaflets out of nine with disease symptoms. Severity was the proportion of leaflet area covered by lesions, determined visually by estimating a percentage of diseased area (3).

Data analysis. A mixed linear model analysis of variance (ANOVA) was used to determine effects of $T, W$, and $A$ on incidence and severity (10). The logit transformation was used to derive a linear scale and approximately stabilize variances, and the same analysis were performed for both the Honeoye and Earliglow experiments. The equation for the mixed linear model is:

$\operatorname{logit}(Y)_{i j k l}=R_{i}+T_{j}+W_{k}+A_{l}+$

$(T \times W)_{j k}+(T \times A)_{j l}+(W \times A)_{k l}+$

$(T \times W \times A)_{i k l}+\varepsilon_{i j k l}$

in which $Y$ is either disease incidence or severity; $R_{i}$ is the effect of $i$ th repetition ( $i$ $=1,2,3)$, considered as a random effect; $T_{j}$ is the effect of the $j$ th temperature $(j=1$, $\ldots, 6) ; W_{k}$ is the effect of the $k$ th wetness duration $(k=1, \ldots, 6)$, considered a temporally repeated measure; $A_{1}$ is the effect of the $l$ th leaflet age $(l=1,2,3)$, considered a spatially repeated measure; $\varepsilon_{i j k l}$ is the error term (unexplained variability); $(T \times W)_{j k}$ is the interaction of $T_{j}$ and $W_{k} ;(T \times A)_{j l}$ is the interaction of $T_{j}$ and $A_{l} ;(W \times A)_{k l}$ is the interaction of $W_{k}$ and $A_{l}$; and $(T \times W \times A)_{i k l}$ is the three-way interaction among $T_{j}, W_{k}$, and $A_{l}$. For the repeated measures, it was assumed that there was a first-order autoregressive relation for the correlation of disease over time (i.e., wetness durations) and an unstructured correlation relation for disease among leaflet ages (10). $F$ tests were used to determine if main effects or their interactions significantly affected logit of disease. Degrees of freedom for the $F$ tests was calculated using the Satterthwaite method (10). Least squares means of logits were calculated for all main effects and their interactions. Least squares means are predicted expected values of logits based on the estimated parameters in the model.

In the mixed linear model ANOVA, temperature and wetness duration (and their interactions) were considered as so-called class (category) variables. Based on the significant effects in the analysis, prediction models were determined by treating temperature and wetness duration as continuous variables in a mixed linear model. Essentially, this is analogous to a multiple regression analysis that also corrects for the correlation of the temporally and spatially repeated measures.

\section{RESULTS}

Cultivar Honeoye. $W, T, A$, and the interaction of $W$ and $A$ all had significant effects $(P<0.05)$ on the logit of disease incidence (Table 1). The interaction indicates that the increase in $\operatorname{logit}(Y)$ with increasing wetness duration depended on leaflet age. The combined effects of $W$ and $A$ can be seen in the plots of means in Figure $1 \mathrm{~A}$ and $\mathrm{B}$. Although the analysis was based on logits (Fig. 1B), mean percentages of infected leaflets also were shown (Fig. 1A) to allow easier interpretation of statistical results.

Mean disease incidence decreased with increasing leaflet age (Fig. 1A and B). For instance, at $15 \mathrm{~h}$ of wetness, mean incidence was $93 \%$ for the youngest leaflets and only $14 \%$ for the oldest leaflets. The interaction of $W$ and $A$ can be seen as the somewhat more rapid increase in the mean logit of incidence overall for the intermediate age leaflets compared with the other ages, and the more rapid increase between 5 and $10 \mathrm{~h}$ of wetness for the youngest leaflets compared with the more gradual increase in mean logits for the other ages at these two wetness durations.

The significant main effect of $T$ is shown by the plot of means in Figure 2A and $\mathrm{B}$. Incidence increased noticeably between 10 and $20^{\circ} \mathrm{C}$; for instance, mean incidence across all leaflet ages increased

Table 1. Effect of temperature, leaflet wetness duration, leaflet age, and their interactions on the logit of disease incidence and severity based on a mixed model analysis of variance on cv. Honeoye

\begin{tabular}{|c|c|c|c|c|c|c|c|c|}
\hline \multirow[b]{2}{*}{ Effect $^{b}$} & \multicolumn{4}{|c|}{ Disease incidence $^{a}$} & \multicolumn{4}{|c|}{ Disease severity $^{a}$} \\
\hline & $\mathbf{d f}_{\mathrm{n}}$ & $\mathbf{d f}_{\mathrm{d}}$ & $F$ & Probability & $\mathbf{d f}_{\mathrm{n}}$ & $\mathbf{d f _ { d }}$ & $F$ & Probability \\
\hline Temperature $(T)$ & 5 & 16.5 & 3.10 & 0.037 & 5 & 18.3 & 1.01 & 0.438 \\
\hline Wetness $(W)$ & 5 & 69.8 & 56.40 & $<0.001$ & 5 & 77.5 & 32.19 & $<0.001$ \\
\hline$T \times W$ & 25 & 69.8 & 0.82 & 0.699 & 25 & 77.5 & 1.00 & 0.480 \\
\hline Leaflet age $(A)$ & 2 & 53.5 & 400.90 & $<0.001$ & 2 & 44.7 & 384.78 & $<0.001$ \\
\hline$T \times A$ & 10 & 53.5 & 0.62 & 0.794 & 10 & 44.7 & 0.49 & 0.891 \\
\hline$W \times A$ & 10 & 87.4 & 4.13 & $<0.001$ & 10 & 89.9 & 1.87 & 0.055 \\
\hline$T \times W \times A$ & 50 & 87.4 & 1.12 & 0.313 & 50 & 89.9 & 0.69 & 0.925 \\
\hline
\end{tabular}

${ }^{a}$ Numerator degrees of freedom $\left(\mathrm{df}_{\mathrm{n}}\right)$ and denominator degrees of freedom $\left(\mathrm{df}_{\mathrm{d}}\right)$; degrees of freedom calculated using the Satterthwaite formula for a mixed model; $F$ statistic for testing effect and probability (significance) level of $F$ statistic.

${ }^{\mathrm{b}} W$ and $A$ were repeated measurements. An autoregressive covariance structure was used for $W$, and an unstructured covariance was used for $A$. 
from $42 \%$ at $10^{\circ} \mathrm{C}$ to $61 \%$ at $20^{\circ} \mathrm{C}$. There also was a decrease in mean incidence between 30 and $35^{\circ} \mathrm{C}$. There was no significant interaction of $T$ with the other factors (Table 1 ); therefore, $T$ did not affect the rate of increase in logit of incidence with increasing wetness duration or affect the change in mean incidence with increasing leaflet age (Fig. 3).

Both $W$ and $A$, and their interaction, significantly affected the logit of disease severity (Table 1). As with disease incidence, mean severity increased with decreasing leaflet age and increased with wetness duration (Fig. 1C and D). The interaction also indicated that the increase in logit of severity with $W$ depended on leaflet age. However, the differences among the three leaflet ages in the increase in severity with $W$ were slight (Fig. 1D).

Unlike the case for incidence, temperature did not have a significant effect on the logit of severity (Table 1). This can be seen by the very similar logit means between 20 and $35^{\circ} \mathrm{C}$ (Fig. 2D). Although there was an apparent small increase in observed means between 10 and $20^{\circ} \mathrm{C}$, the change was not large enough to be significant because of the degree of variation (see standard errors).

Cultivar Earliglow. W, A, and their interaction had significant effects on the logit of disease incidence and severity (Table 2). The relationship between means and wetness duration and leaflet age was very similar to that of cv. Honeoye (Fig. 3B and D).

$T$ did not have a significant effect on either the logit of incidence or severity (Table 2). This result for incidence is different from that obtained from Honeoye (Table 1 ), possibly because only three temperatures were tested with Earliglow. No significant two-way interactions of $T$ and the other factors were observed. There was a significant three-way interaction for incidence; however, inspection of the means did not reveal any consistent effect that temperature had on the interaction of wetness duration and leaflet age (M. Nita, unpublished).

Prediction models. $T, W, A$, and $W \times A$ had significant effects with disease incidence of Honeoye (Table 1); therefore, the following model was fitted to the data.

$\operatorname{logit}(Y)_{i l}=R_{i}+\beta_{1} T+\beta_{2} T^{2}+\beta_{3 l}+$

$\beta_{4} W+\beta_{5 l} W+\varepsilon_{i l}$

in which $\operatorname{logit}(Y)_{i l}$ is logit of incidence for the $i$ th repetition and $l$ th leaflet age $(l=1$, 2,3 ), and the $\beta$ s are parameters. In this model version, temperature and wetness durations are continuous variables, so they are written without subscripts; $\beta_{1}$ and $\beta_{2}$ are coefficients of $T$ and $T^{2}$, respectively; $\beta_{3 l}$ represents the effect of leaflet age on logit of incidence; $\beta_{4}$ is the coefficient of $W$; and $\beta_{5 l}$ represents the effects of the $l$ th leaflet age on the rate of increase in logit with increase in wetness duration (i.e., effect of leaflet age on the slope). It was assumed that logit of incidence increased in a linear fashion with $W$, and that there was a quadratic relationship between logit and temperature. It should be noted that the symbols $\beta_{3 l}$ and $\beta_{5 l}$ actually represent three parameters each (i.e., $\beta_{31}, \beta_{32}, \beta_{33}$, and $\beta_{51}$, $\beta_{52}, \beta_{53}$ ), where the second subscript number is the label for leaflet age.

Equation 2 can be written more succinctly as:

$\operatorname{logit}(Y)_{i l}=R_{i}+\beta_{1} T+\beta_{2} T^{2}+\beta_{3 l}+$

$$
\left(\beta_{4}+\beta_{5 l}\right) W+\varepsilon_{i l}
$$

The expected value of $R_{i}$ (the effect of repetition) is 0 (10); therefore, it can be ignored in making mean predictions. In terms of leaf wetness duration, this is an equation for a straight line with slope given by $\beta_{4}+\beta_{5 l}$ and the intercept given by $\beta_{1} T$ $+\beta_{2} T^{2}+\beta_{3 l}$. The intercept can be considered a measure of the height of the line. Parameter estimates are given in Table 3. Coefficient of determination $\left(R^{2}\right)$, based on squaring the correlation between

\section{Percentage}
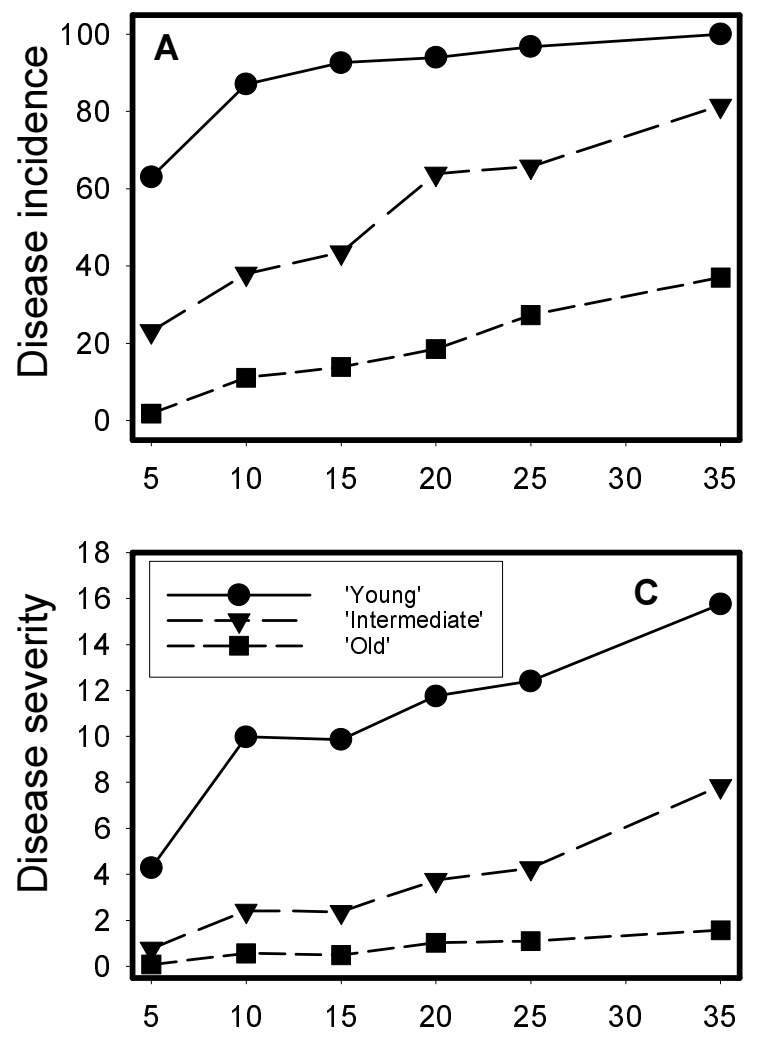

Logit
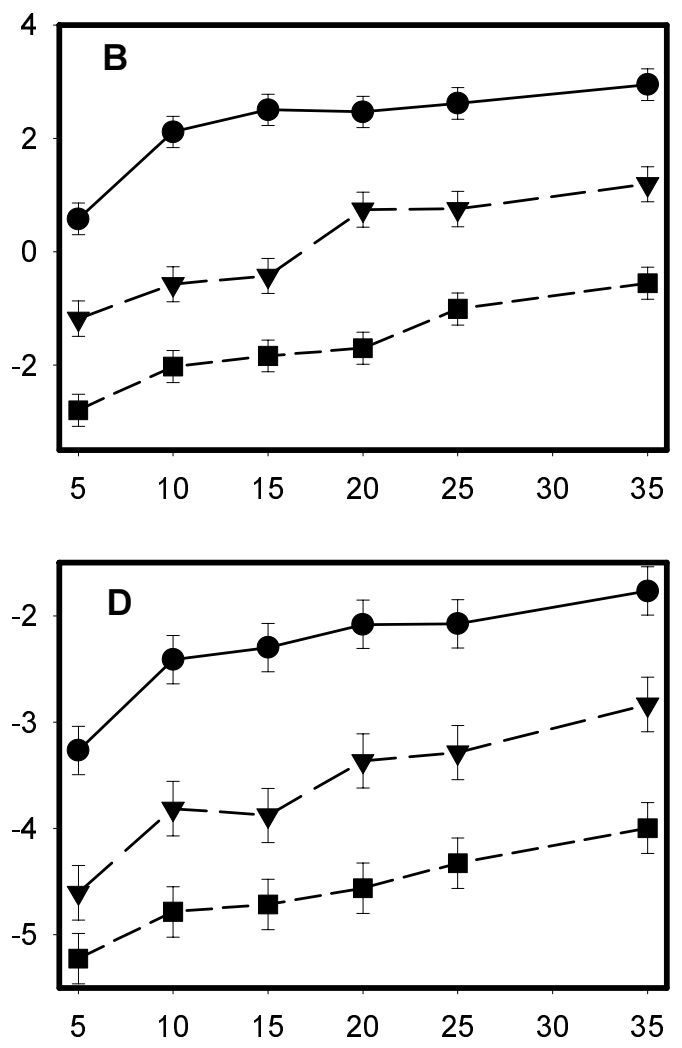

\section{Leaf wetness duration}

Fig. 1. Effects of leaflet wetness duration (hours) and leaflet age of strawberry on disease incidence and severity. A and $\mathbf{C}$, Mean percentage of infected leaflets; B and D, least squares means from a mixed model analysis of variance for cv. Honeoye. Standard error bars are shown only for logits because analyses are based on the logits. 
the observed and predicted logits, was 0.81 . Estimated values of $\beta_{3 l}$ show how the predicted logits decrease with increasing leaflet ages. The estimates of $\beta_{4}+\beta_{5 l}$ show that the fastest increase in logit with $W$ corresponded to the intermediate leaflet age $(0.100 / \mathrm{h})$, and that of the other two leaflet ages had very similar rates of increase with $W$. However, the difference in rates between the intermediate and other ages was only slight, which also can be seen in Figure 1B.

The effect $T$ was not significant for logit of severity of cv. Honeoye (Table 1); therefore, the prediction equation simplifies to:

$$
\operatorname{logit}(Y)_{i l}=R_{i}+\beta_{3 l}+\left(\beta_{4}+\beta_{5 l}\right) W+\varepsilon_{i l}
$$

The intercept of equation 4 is given by $\beta_{3 l}$ (i.e., dependent on leaflet age), and the slope (with respect to $W$ ) is given by $\beta_{4}+\beta_{5 l}$. $R_{2}$ was 0.80 . As with disease incidence, the estimated intercept decreased with increasing leaflet age (Table 3; Fig. 3B and $\mathrm{D}$ ), and the slope (rate of increase in logit with $W$ ) was highest for the intermediate age leaflets. The slopes were all lower for logit of severity than for logit of incidence, reflecting the considerably greater increase in logit of incidence than in severity with increasing wetness duration.
In order to directly compare intercepts (line heights) for incidence and severity, one has to choose a "standard" temperature because the intercept for incidence depends on temperature (equation 3). At $T^{*}=$ $22.5^{\circ} \mathrm{C}$, the midpoint of tested temperatures, one can estimate the intercept for incidence as: $0.185 \cdot 22.5-0.004 \cdot\left(22.5^{2}\right)+$ $\hat{\beta}_{3 l}$ where $\hat{\beta}_{3 l}$ represents the estimated $\beta_{3 l}$ parameters. These estimated intercepts equal $1.03,-1.57$, and -2.89 for young, intermediate, and old leaflets, respectively. These values are all substantially larger than the estimated $\beta_{3 l}$ values (i.e., intercepts) for severity (Table 3 ), reflecting the considerably higher incidence than severity.

Equation 4 is the appropriate model to use for both disease incidence and severity with cv. Earligrow because of the lack of temperature effect. Results were similar to those obtained for Honeoye (Table 3 ). $R^{2}$ values were about 0.8 . The greatest rate of increase with wetness duration corresponded to the intermediate age leaflets, although the differences in slopes were not great (Table 3). Moreover, intercepts decreased with increasing leaflet age, an indication of the increasing resistance of older leaflets. Finally, intercepts and slopes were larger for incidence than for severity.

\section{DISCUSSION}

Our results generally indicated an increasing trend of disease intensity (incidence and severity) of Phomopsis leaf blight of strawberry with increasing leaflet wetness duration during the inoculation period and decreasing leaflet ages (Figs. 1 and 3). Results were determined primarily for Honeoye and confirmed with Earliglow. Interactions of wetness duration and leaflet age also were observed consistently, indicating the rate of increase in logit of disease intensity with wetness duration depended on leaflet age. However, this interaction did not affect the ranking of disease intensity for the three leaflet ages at any give wetness duration (Figs. 1 and $3)$.

Incidence and severity were most influenced by leaflet age, based on the magnitude of the $F$ statistic (Tables 1 and 2), followed by leaf wetness duration. Highest disease intensity was found for the youngest leaflets, and the means declined directly with age (Fig. 1B). Typically, incidence and severity means were about four to five times higher with the youngest leaflets compare with the oldest (Fig. 1B and D). The leaflets probably develop some types of ontogenic resistance with aging $(1,15)$. These results were comparable to the
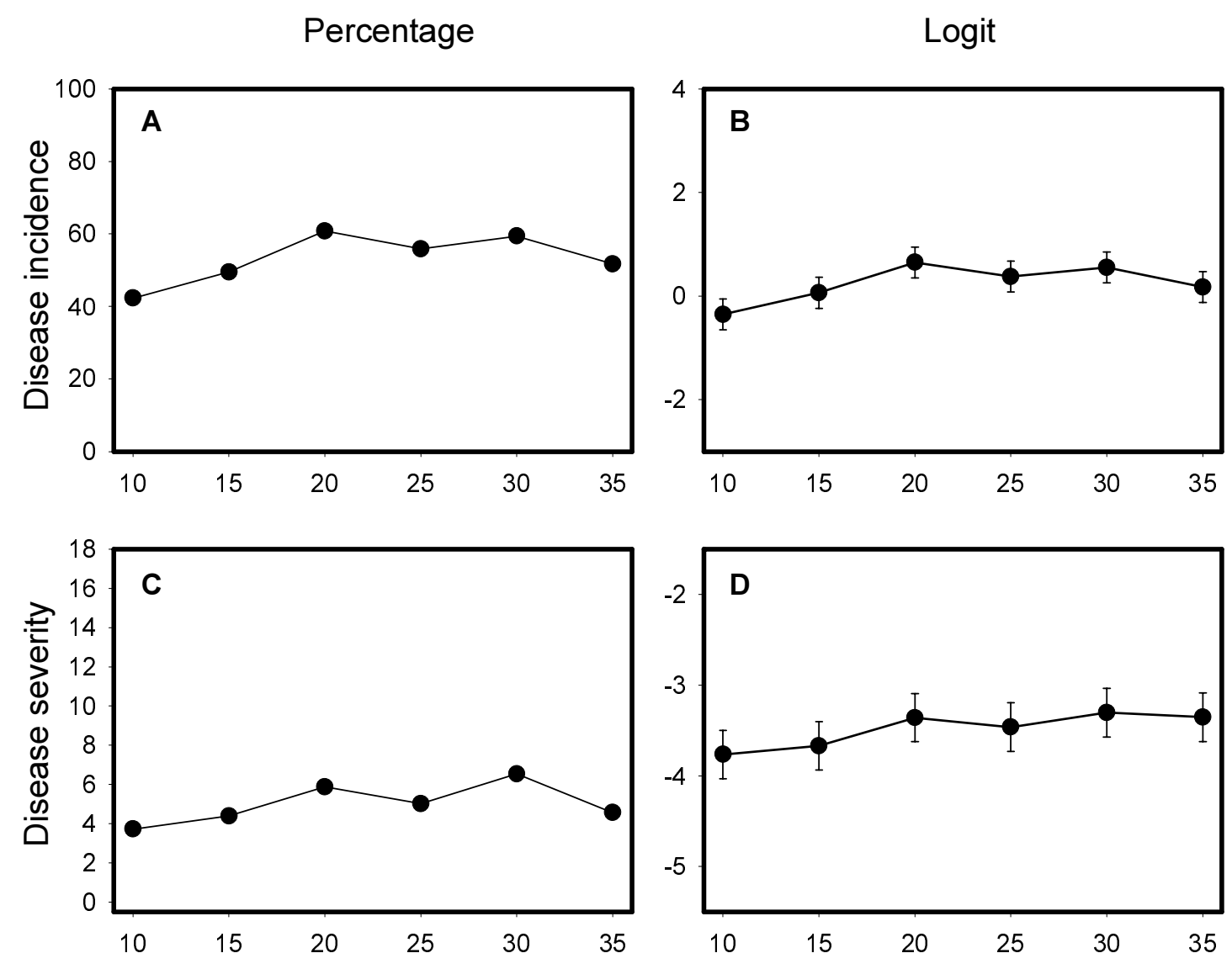

\section{Temperature}

Fig. 2. Effects of temperature $\left({ }^{\circ} \mathbf{C}\right)$ on mean disease incidence and severity. $\mathbf{A}$ and $\mathbf{C}$, Mean percentage of infected leaflets; $\mathbf{B}$ and $\mathbf{D}$, least squares means from a mixed model analysis of variance for cv. Honeoye. Standard error bars are shown only for logits because analyses are based on the logits. 
results from Eshenaur and Milholland (5) in North Carolina, who also found a similar relationship between leaflet ages and disease intensity for 'Sparkle', which is a short-day late-season cultivar.

Both mean disease incidence and severity for Honeoye increased in mostly a linear manner with wetness duration, except for a more rapid increase between wetness durations of 5 and $10 \mathrm{~h}$ (Fig. 1B and D). In their previous study, Eshenaur and Milholland (5) showed an increase in disease intensity with wetness durations of 1 to 5 days, but they only studied a single temperature, $20^{\circ} \mathrm{C}$. By $35 \mathrm{~h}$ in our study, mean disease incidence on the youngest leaflets was already $100 \%$ (mean across all temperatures), while mean severity was $19 \%$ (Fig. 1). Clearly, this disease is favored by very long wetness periods. However, short wetness durations are sufficient for infection. With as little as $5 \mathrm{~h}$ of wetness, over $60 \%$ of the youngest leaflets became infected, on average.

Significant effects of temperature were found only with disease incidence on Honoeye (Table 1). Even in this case, the response to the temperature between 10 and $35^{\circ} \mathrm{C}$ was only slight (Fig. 2). For instance, mean incidence (across all wetness duration and leaflet ages) ranged from a minimum of 42 to $61 \%$ (Fig. 2). It is unclear why temperature did not have a stronger effect between 10 and $35^{\circ} \mathrm{C}$, considering that spore germination is influenced by temperature (5; M. Nita, unpublished). Previously, Eshenaur and Milholland (5) showed that temperature during the post-inoculation period, which lasted up to 30 days, had an effect on disease intensity. They found that disease increased with temperatures up to $30^{\circ} \mathrm{C}$ (the highest tested) during the period. They did not evaluate temperatures during the inoculation period at a range of wetness durations. It is possible that the temperature response found by Eshenaur and Milholland (5) is reflecting the increasing rate of leaflet maturation and senescence with increasing temperature, and the corresponding correlation of symptom development with aging (6). In our study, a high temperature stress was successfully used to promote rapid symptom development.

A linear mixed model with a logit transformation of disease incidence and severity (equations 3 and 4) was found to provide a precise description of the data sets (Table 3). This is not surprising because others have found a logistic model appropriate for describing similar data $(2,7,19)$. Because of recent advances in mixed-model theory and computation (10), the random effect of repetition and the correlation of disease among leaflet ages and over time on the same plants could be accounted for in the data analysis. A linear (straight-line) relationship between logit and $W$ was satisfactory for describing the increase in disease intensity with increase in wetness duration, and quantified the (slightly) greater rate of disease increase for the intermediate-aged leaflets compared with the others. The linear relationship could not capture the rapid increase in disease between 5 and $10 \mathrm{~h}$ of wetness duration for the youngest leaflets, but this nonlinearity was not great enough to justify more complicated functions for the $W$ term. In fact, models that used transformation of $W$ (e.g., $W^{1 / 2}$ ) did not fit the data overall as well as models used here (M. Nita, unpublished).

In conclusion, susceptibility of strawberry leaflets to infection by $P$. obscurans decreased with leaflet age, and infection for all leaflet ages increased with wetness duration. Temperature between 10 and $35^{\circ} \mathrm{C}$ had only a minor, or no, effect on infection. Symptom expression was slow even with post-inoculation stress on plants, and lesions were often not visible before the third week after inoculation (5). This may explain why disease symptoms are

\section{Percentage}
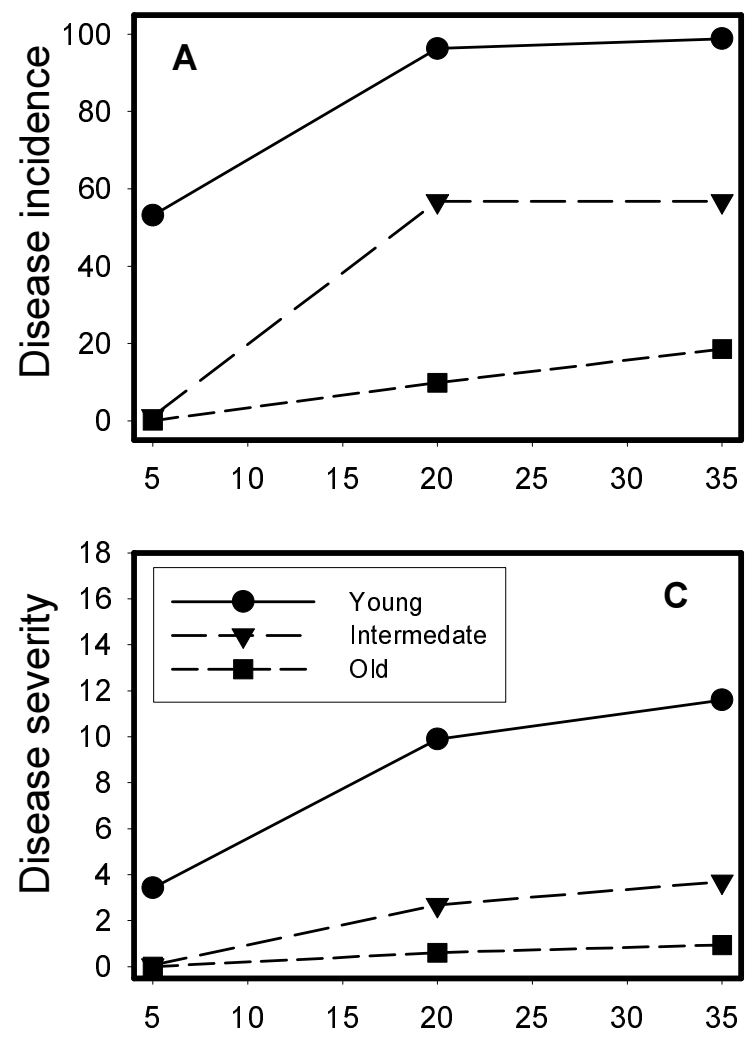

Logit
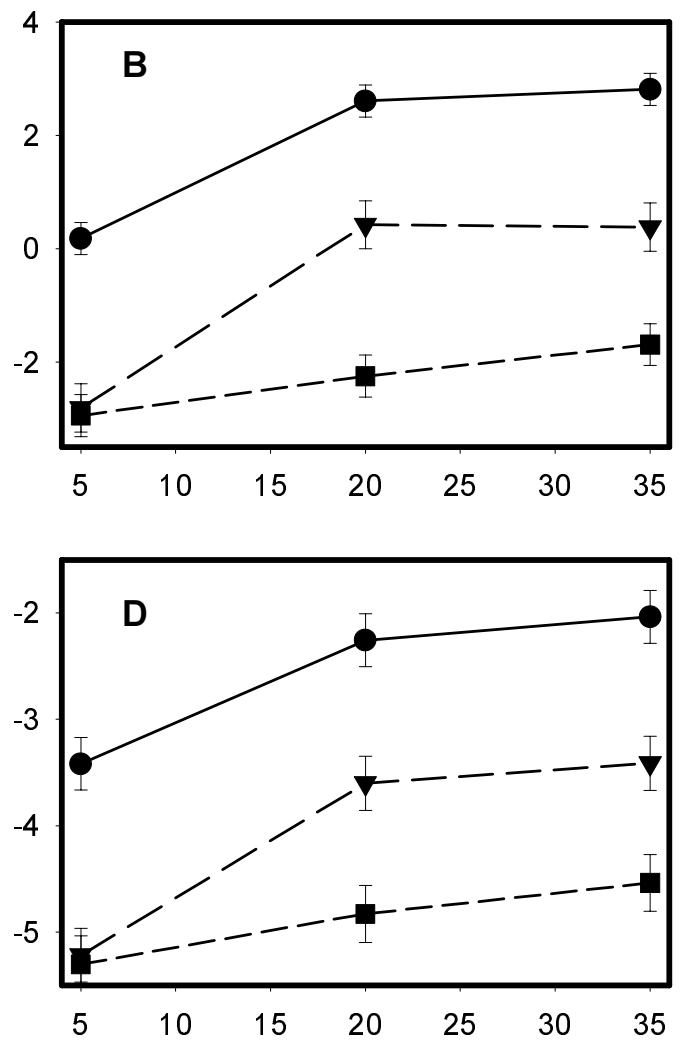

Leaf wetness duration

Fig. 3. Effects of leaflet wetness duration (hours) and leaflet age of strawberry on disease incidence and severity. A and $\mathbf{C}$, Mean percentage of infected leaflets; B and D, least squares means from a mixed model analysis of variance for cv. Earliglow. Standard error bars are shown only for logits because analyses are based on the logits. 
Table 2. Effect of temperature, leaflet wetness duration, leaflet age, and their interactions on the logit of disease incidence and severity based on a mixed model analysis of variance on cv. Earliglow

\begin{tabular}{|c|c|c|c|c|c|c|c|c|}
\hline \multirow[b]{2}{*}{ Effect $^{b}$} & \multicolumn{4}{|c|}{ Disease incidence $^{a}$} & \multicolumn{4}{|c|}{ Disease severity $^{a}$} \\
\hline & $\mathbf{d f}_{\mathbf{n}}$ & $\mathbf{d f}_{\mathrm{d}}$ & $F$ & Probability & $\mathbf{d f}_{\mathbf{n}}$ & $d f_{d}$ & $F$ & Probability \\
\hline Temperature $(T)$ & 2 & 5.82 & 0.07 & 0.933 & 2 & 5.82 & 0.06 & 0.943 \\
\hline Wetness $(W)$ & 2 & 10.4 & 32.68 & $<0.001$ & 2 & 14.6 & 29.14 & $<0.001$ \\
\hline$T \times W$ & 4 & 10.4 & 0.30 & 0.871 & 4 & 14.6 & 0.57 & 0.686 \\
\hline Leaflet age $(A)$ & 2 & 10.4 & 80.82 & $<0.001$ & 2 & 10.1 & 76.79 & $<0.001$ \\
\hline$T \times A$ & 4 & 10.4 & 0.04 & 0.997 & 4 & 10.1 & 0.05 & 0.995 \\
\hline$W \times A$ & 4 & 14 & 16.76 & $<0.001$ & 4 & 13 & 4.48 & 0.017 \\
\hline$T \times W \times A$ & 8 & 14 & 3.39 & 0.022 & 8 & 13 & 1.49 & 0.250 \\
\hline
\end{tabular}

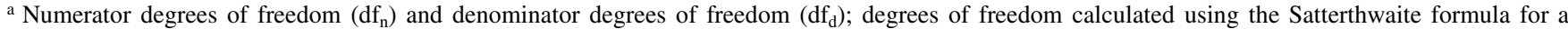
mixed model; $F$ statistic for testing effect and probability (significance) level of $F$ statistic.

${ }^{\mathrm{b}} W$ and $A$ were repeated measurements. An autoregressive covariance structure was used for $W$, and an unstructured covariance was used for $A$.

Table 3. Estimated parameters of the prediction models for the logit of Phomopsis leaf blight disease incidence and severity for two strawberry cultivars

\begin{tabular}{|c|c|c|c|c|c|c|}
\hline \multirow[b]{2}{*}{ Leaflet age } & \multicolumn{4}{|c|}{ Disease incidence $^{a}$} & \multicolumn{2}{|c|}{ Disease severity $^{b}$} \\
\hline & $\beta_{1}$ & $\beta_{2}$ & $\beta_{31}$ & $\left(\beta_{4}+\beta_{51}\right)$ & $\beta_{31}$ & $\left(\beta_{4}+\beta_{51}\right)$ \\
\hline \multicolumn{7}{|l|}{ Honeoye } \\
\hline Young & 0.185 & -0.004 & -1.099 & 0.066 & -3.171 & 0.044 \\
\hline Intermediate & 0.185 & -0.004 & -3.704 & 0.100 & -4.667 & 0.055 \\
\hline Old & 0.185 & -0.004 & -5.022 & 0.071 & -5.325 & 0.039 \\
\hline \multicolumn{7}{|l|}{ Earliglow } \\
\hline Young & $\ldots$ & $\ldots$ & 0.089 & 0.088 & -3.500 & 0.046 \\
\hline Intermediate & $\ldots$ & $\ldots$ & -2.828 & 0.106 & -5.294 & 0.060 \\
\hline Old & $\ldots$ & $\ldots$ & -3.131 & 0.042 & -5.402 & 0.025 \\
\hline
\end{tabular}

a Honeoye: estimation of parameters for equation 2 ; coefficient of determination $\left(R^{2}\right)$ was 0.81 . Earliglow: estimation of parameters for equation $3 ; R^{2}$ was 0.81 .

${ }^{\mathrm{b}}$ Honeoye: estimation of parameters for equation $3 ; R^{2}$ was 0.80 . Earliglow: estimation of parameters for equation $3 ; R^{2}$ was 0.81 .

found mostly on older leaflets in the field, typically around harvest when leaflets are beginning to senesce, even though infections probably are occurring on younger foliage. During the spring and early summer in Ohio, strawberry plants are continuously producing new foliage; thus, there is always highly susceptible young foliage available for infection by $P$. obscurans. Nevertheless, disease intensity varies greatly among farms and years $(17,18)$, presumably because of variation of wetness conditions and other factors. The prediction model we developed (equations 3 and 4) should be useful to identify infection periods with this disease, and to help schedule fungicide applications $(2,3,7,19)$. Unlike many diseases $(2,7,12,19)$, however, typical temperatures during infection periods may be of minor value in predicting infection.

\section{LITERATURE CITED}

1. Boyle, C., and Aust, H. J. 1997. Ontogenetically determined resistance (adult plant resis- tance). Pages 254-271 in: Resistance of Crop Plants Against Fungi. H. Hartleb, R. Heitefuss, H.-H. Hoppe, eds. Gustav Fischer Verlag, Jena, Berlin, Germany.

2. Bulger, M. A., Ellis, M. A., and Madden, L. V. 1987. Influence of temperature and wetness duration of strawberry flowers by Botrytis cinerea and disease incidence of fruit originating from infected flowers. Phytopathology 77:1225-1230.

3. Campbell, L. C., and Madden, L. V., 1990. Introduction to Plant Disease Epidemiology. John Wiley \& Sons, New York.

4. Ellis, M. A., 1998. Strawberry leaf spot diseases. Ohio State University Extension Fact Sheet HYG.-3015-95. Ohio State University, Columbus.

5. Eshenaur, B. C., and Milholland, R. D. 1989. Factors influencing the growth of Phomopsis obscurans and disease development on strawberry leaf and runner tissue. Plant Dis. 73:814-819.

6. Fracas, G. L. 1978. Senescence's and plant disease. Pages: 391-412 in Plant Disease: An Advanced Treatise, Volume III. J. G. Shortfall and E. B. Cowling, eds. Academic Press, New York.

7. Grove, G. G., Madden, L. V., Ellis, M. A., and Schmitthenner, A. F. 1985. Influence of tem- perature and wetness duration on infection of immature strawberry fruit by Phytophthora cactorum. Phytopathology 75:165-169.

8. Kerkhoff, K. L., Williams, J. M., and Barden, J. A. 1988. Effects of defoliation on growth and yield of 'Redchief' strawberries. Adv. Strawberry Prod. 7:26-28.

9. Legard, D. E., Whidden, A. J., and Chandler, C. K. 1997. Incidence and occurrence of strawberry diseases in Florida from 19911996. Adv. Strawberry Res. 16:35-47.

10. Littell, R. C., Milliken, G. A., Stroup, W. W., and Wolfinger, R. D. 1996. SAS System for Mixed Models. SAS Institute, Inc, Cary, N.C.

11. Maas, J. L. 1985. New symptoms of strawberry leaf blight disease. Adv. Strawberry Prod. 4:34-35.

12. Maas, J. L., ed. 1998. Compendium of Strawberry Diseases. Second ed. The American Phytopathological Society, St. Paul, MN.

13. Nita, M., Madden, L. V., and Ellis, M. A., 2000. Evaluation of fungicides and fungicide combinations for control of leaf blight, 1999. Fungic. Nematicide Tests 55:133.

14. Nita, M., Madden, L. V., and Ellis M. A., 2001. Evaluation of fungicides and fungicide combinations for control of leaf blight, 2000. Fungic. Nematicide Tests 56:SMF46.

15. Popular, C. 1978. Changes in host susceptibility with time. Pages 239-260 in: Plant Disease: An Advanced Treatise. Volume II. J. G. Horsfall and E. B. Cowling, eds. Academic Press, New York.

16. Sutton, B. C., and Waterson, J. M. 1970 Phomopsis obscurans C.M.I. Description of Pathogenic Fungi and Bacteria No. 227.

17. Turechek, W. W., Ellis, M. A., and Madden, L. V., 2001. Sequential sampling for incidence of Phomopsis leaf blight of strawberry. Phytopathology 91:336-347.

18. Turechek, W. W., and Madden, L. V., 1999. Spatial pattern analysis of strawberry leaf blight in perennial production systems. Phytopathology 89:421-433.

19. Wilson, L. L., Madden, L. V., and Ellis, M. A. 1990. Influence of temperature and wetness duration on infection of immature and mature strawberry fruit by Colletotrichum acutatum. Phytopathology 80:111-116. 